\title{
Electrochemical and Spectroelectrochemical Characterization of Some Polypyrrole/Anthraquinone Sulfonate Films
}

\author{
S. M. Ahmed, Tsutomu NagaokA ${ }^{\dagger}$ and Kotaro OGRA \\ Department of Applied Chemistry, Faculty of Engineering, Yamaguchi University, Tokiwadai, Ube 755, Japan
}

\begin{abstract}
We have fabricated composite films of polypyrrole/quinone sulfonate via electropolymerization. The FTIR investigation indicated the incorporation of quinone sulfonate in the polypyrrole (PPy) film to compensate for a positive charge in the polymer chain. Further, the elemental analysis of PPy/9,10-anthraquinone-2-sulfonate (AQS ${ }^{-}$) showed that 0.29 of the sulfonate was incorporated per pyrrole unit. Cyclic voltammetric results in dimethylsulfoxide and dimethylformamide solutions showed that the two 1-electron transfer steps could be assigned to the formation of radical dianion (AQS ${ }^{2-}$ ) and trianion $\left(\mathrm{AQS}^{3-}\right)$. The positive shift of the first cathodic peak for the incorporated AQS- indicated a strong interaction between the dianion and the cationic sites of the polymer. The PPy/AQS- film worked as a cation-exchanger at electrode potentials below about $-0.3 \mathrm{~V} v s$. $\mathrm{Ag} / \mathrm{AgCl}$ (saturated $\mathrm{KCl}$ ) because of the creation of the anionic sites of the reduced quinone.
\end{abstract}

Keywords Polypyrrole, anthraquinone sulfonate sodium salt, cation exchange property

Conducting polymer films incorporating electroactive species have been used for sensor applications, and the redox properties have been utilized in charge-storage devices such as super-capacitors and batteries..$^{1-6}$ The optical properties associated with redox switching in some conducting polymers have been studied for possible use in electrochromic devices with high coloration efficiencies. ${ }^{7-14}$ Polypyrrole (PPy) is one of the most useful conducting materials, since it polymerizes easily, forms a membrane readily and has high conductivity and chemical stability. ${ }^{15-17}$ Moreover, since it is easy to combine PPy with other anionic molecules, many functional composites with various properties have been investigated. ${ }^{18-20}$ Especially, the PPy/quinone film is of analytical importance for the application in electrocatalysis and enzyme sensors. ${ }^{21-23}$

In connection with our study, charge transfer of pyrrole copolymers substituted by anthraquinone, phenothiazine, or anthracene moieties has been reported. ${ }^{24-26}$ The electrical conductance of PPy films doping with various anthraquinone and naphthalene sulfonates appears to be very well correlated to the number of sulfonate groups attached, with the highest conductance attained at one sulfonate group per dopant molecule. ${ }^{27-29}$ Hepel has shown that the electrochemical quartz crystal microbalance (EQCM) technique can be used successfully to examine the doping level and the ion transport rate. ${ }^{30}$

In this research, we prepared several composite films

$\dagger$ To whom correspondence should be addressed.

S. M. A. permanent address: Assiut University, Faculty of Science, Department of Chemistry, Assiut, Egypt. consisting of polypyrrole and quinone sulfonates in aqueous solution by using electropolymerization techniques. FTIR spectral measurements and elemental analysis of PPy/9,10-anthraquinone-2-sulfonate (AQS-) revealed that the quinone sulfonates were incorporated in the polypyrrole matrix. Cyclic voltammetry and spectroelectrochemistry indicated the formation of diand trianions of $\mathrm{AQS}^{-}$during the reduction of the film. Further, it was found that the PPy/AQS- could function as a cation-exchanger at electrode potentials below about $-0.3 \mathrm{~V} v s$. $\mathrm{Ag} / \mathrm{AgCl}$.

\section{Experimental}

\section{Materials}

Pyrrole (Wako Chemicals Co.) was used without further purification. All quinones used here were reagent grade and were purified by vacuum sublimation or recrystallization when impurities were found in voltammograms. Tetraethylammonium perchlorate (TEAP) was dried in a vacuum and stored over $\mathrm{P}_{2} \mathrm{O}_{5}$. Milli-Q water was used throughout our experiments. Reagent grade dimethylsulfoxide (DMSO) and dimethylformamide (DMF) were used as received from Wako Chemicals.

\section{Equipment and procedures}

Glassy carbon (GC) electrodes (Tokai, grade GC-20, diameter $3 \mathrm{~mm}$ ) were polished with fine alumina (60 $\mu \mathrm{m})$ and then sonicated for $5 \mathrm{~min}$. Gold plated semitransparent plastic films (FM-1 Courtaulds Performance Films, USA, $1.75 \mathrm{~cm}^{2}$ ) were used as 
working electrodes in spectroelectrochemical experiments. All the potentials reported here were referred to an aqueous $\mathrm{Ag} / \mathrm{AgCl}$ (sat. $\mathrm{KCl}$ ) electrode. FTIR-spectra were measured with a HORIBA Model FT-710 spectrometer. The spectroelectrochemistry of PPy/AQS ${ }^{-}$films was studied with a Shimadzu UV1200 spectrometer controlled with an Apple Macintosh computer.

To prepare $\mathrm{PPy} / \mathrm{Cl}^{-}$, pyrrole $(0.5 \mathrm{M})$ was polymerized under potentiostatic conditions $(+0.80 \mathrm{~V})$ in an aqueous solution containing $0.1 \mathrm{M} \mathrm{KCl}$. For preparation of PPy/ $\mathrm{AQS}^{-}$, an aqueous solution containing pyrrole $(0.5 \mathrm{M})$ and anthraquinone sulfonate $(0.1 \mathrm{M})$ was electrolyzed at $+0.80 \mathrm{~V}$. The modified electrodes were then rinsed with water and dried with nitrogen gas before characterization in DMSO or DMF. All experiments were carried out under ambient temperatures $\left(22 \pm 1^{\circ} \mathrm{C}\right)$, and 0.1 M TEAP DMF or DMSO solutions used for electrochemical measurements were deaerated by passing nitrogen gas through them for about $10 \mathrm{~min}$ before measurements.

\section{Results and Discussion}

The composition of the film

The FTIR-spectra of $\mathrm{AQS}^{-}, \mathrm{PPy} / \mathrm{Cl}^{-}$, and $\mathrm{PPy} / \mathrm{AQS}^{-}$
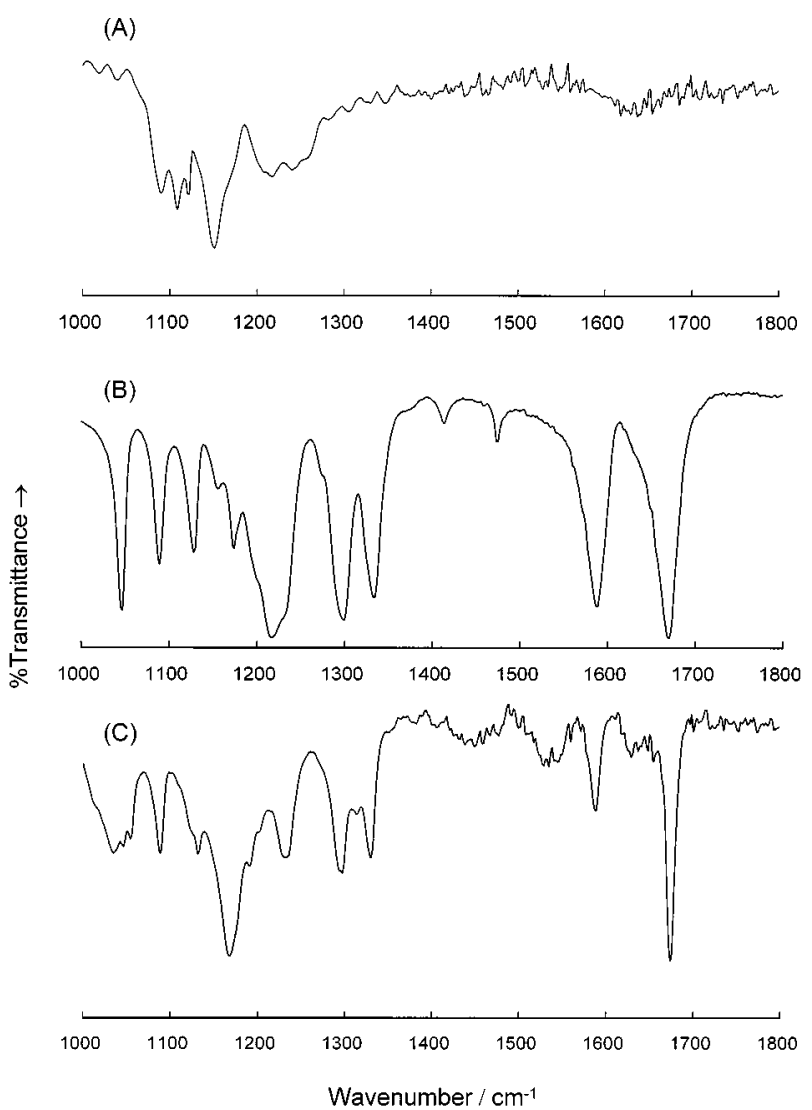

Fig. 1 FTIR-absorption spectra of (A) $\mathrm{PPy} / \mathrm{Cl}^{-}$, (B) $\mathrm{Na}^{+} \mathrm{AQS}^{-}$, and (C) $\mathrm{PPy}^{\mathrm{AQQS}}{ }^{-}$diluted with $\mathrm{KBr}$ powder. films (Fig. 1) demonstrated the $>\mathrm{C}=\mathrm{O}$ stretching vibration for both the authentic $\mathrm{AQS}^{-}(\mathrm{B})$ and corresponding film (C) at almost the same frequency $\left(c a .1670 \mathrm{~cm}^{-1}\right)$. The spectra are good evidence for the immobilization of AQS- in the PPy film to compensate for the positive charge on the polymer chain. Elemental analysis of the PPy/AQS ${ }^{-}$film (\% found: C, $60.78 ; \mathrm{H}, 3.78 ; \mathrm{N}, 8.27 ; \mathrm{S}, 4.77)$ indicated that 0.29 of $\mathrm{AQS}^{-}$was doped electrostatically per pyrrole unit, i.e. $\left.\left\{\left[-\left(\mathrm{C}_{4} \mathrm{H}_{2} \mathrm{NH}\right)_{3}\right]^{+}\right]^{+} \mathrm{AQS}^{-}\right\}_{n}$. It has been pointed out that up to $0.3 \mathrm{AQS}^{-}$ion can be incorporated per pyrrole unit to balance the positive charge and to preserve local electroneutrality. ${ }^{27,31,32}$

\section{Electrochemical study}

The cyclic voltammogram of $5 \mathrm{mM} \mathrm{AQS}^{-}$dissolved in 0.1 M TEAP-DMF solution (Fig. 2A) displayed classical quinone electrochemistry with two well-defined Nernstian processes $\left(E_{1 / 2}=-0.80 \mathrm{~V}\right.$ for AQS-/AQS ${ }^{2-}$, and $-1.35 \mathrm{~V}$ for $\left.\mathrm{AQS}^{2-} / \mathrm{AQS}^{3-}\right)$. Figures $2 \mathrm{~B}$ and $2 \mathrm{C}$ show the cyclic voltammograms of the $\mathrm{PPy} / \mathrm{Cl}^{-}$and $\mathrm{PPy} /$

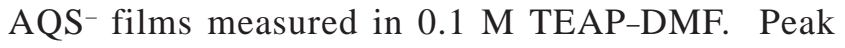
potentials similar to those in Fig. 2 have also been observ-
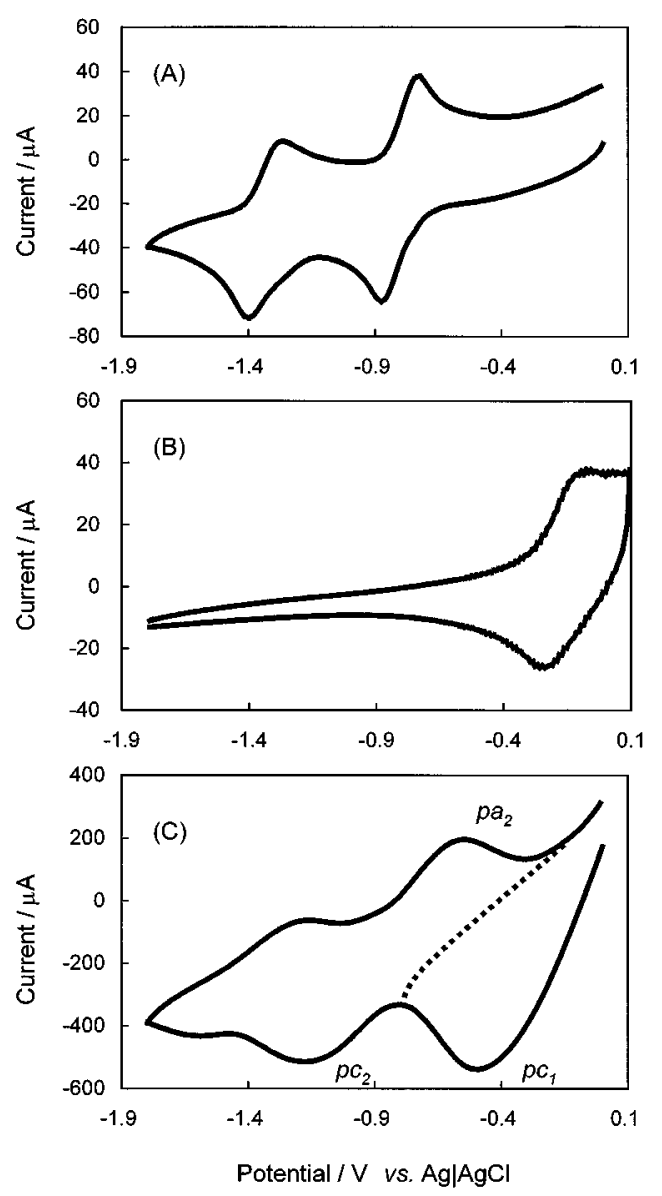

Fig. 2 Cyclic voltammograms of (A) dissolved $5 \mathrm{mM} \mathrm{AQS}^{-}$, (B) $\mathrm{PPy} / \mathrm{Cl}^{-}$, and (C) PPy/AQS- ${ }^{-}$The voltammograms were recorded in $0.1 \mathrm{M}$ TEAP-DMF at scan rates of (A and B) 50 $\mathrm{mV} \mathrm{s}^{-1}$ and (C) $10 \mathrm{mV} \mathrm{s}^{-1}$ at GC electrodes. Electrodeposition of PPy, $+0.8 \mathrm{~V}$ for $5 \mathrm{~min}$. 
ed in DMSO solutions (Table 1). Although the $\mathrm{E}^{\circ \prime}$ for the second reduction of $\mathrm{PPy} / \mathrm{AQS}^{-}\left(\mathrm{pc}_{2}\right)$ was very close to that for the first reduction of the dissolved quinone, the $\mathrm{pc}_{2}$ could not be ascribed to the semiquinone formation because of the following reasons. (1) Spectral measurements, as will be discussed later (Fig. 3), demonstrated that the onset of $\mathrm{AQS}^{-}$reduction appeared at about $-0.3 \mathrm{~V}$. (2) This mechanism failed to explain the positive shifts of the $\mathrm{pc}_{1}$ on the addition of $\mathrm{Li}^{+}$ion (see Fig. 4B), if the $\mathrm{pc}_{1}$ would have arisen solely from the reduction for the cationic sites of PPy. Consequently, it can be concluded that the first and second peaks of PPy/AQS ${ }^{-}$that appeared at more positive potentials than those for the dissolved quinone are to be assigned to the formation of $\mathrm{AQS}^{2-}$. and $\mathrm{AQS}^{3-}$. In addition, the peak for $\mathrm{AQS}^{2-}$ is merged into that for polypyrrole.

The positive shift for the semiquinone formation indicates that $\mathrm{AQS}^{2-}$. was associated with the cationic site of the polymer as follows:

$$
\left[\mathrm{Py}_{3}{ }^{+} \mathrm{AQS}^{-}\right]_{n} \stackrel{+\mathrm{e}^{-}, \mathrm{TEA}^{+}}{\longrightarrow}\left[\mathrm{Py}_{3}{ }^{+} \mathrm{AQS}^{2-} \cdot \mathrm{TEA}^{+}\right]_{n}
$$

where $\mathrm{Py}_{3}$ is the repeating unit of $\mathrm{PPy}$ consisting of three pyrrole rings, i.e. $-\left(\mathrm{C}_{4} \mathrm{H}_{2} \mathrm{NH}\right)_{3}-$, and $\mathrm{TEA}^{+}$is tetraethylammonium ion inserted from the solution phase. However, polymer reduction should also coincide with Eq. (1), as suggested by the voltammogram (Fig. 2 C).

$$
\begin{aligned}
& {\left[\mathrm{Py}_{3}{ }^{+} \mathrm{AQS}^{-}\right]_{n} } \stackrel{+\mathrm{e}^{-}, \mathrm{TEA}^{+}}{\longrightarrow}\left[\mathrm{Py}_{3} \mathrm{AQS}^{-} \mathrm{TEA}^{+}\right]_{n} \\
& \stackrel{+\mathrm{e}^{-}, \mathrm{TEA}^{+}}{\longrightarrow}\left[\mathrm{Py}_{3} \mathrm{AQS}^{2-} \cdot\left(\mathrm{TEA}^{+}\right)_{2}\right]_{n}
\end{aligned}
$$

Ion pairing between anion radical and $\mathrm{TEA}^{+}$is usually negligible in aprotic dipolar solvents, and the interaction in the polymer texture was also assumed to be negligible because of the bulky structure of $\mathrm{TEA}^{+}$.

The positive shift of the second cathodic peak $\left(\mathrm{pc}_{2}\right)$ for $\mathrm{PPy} / \mathrm{AQS}^{-}$means that there is still an interaction between the trianion $\left(\mathrm{AQS}^{3-}\right)$ and the polymer cationic charge (Fig. $2 \mathrm{C}$ and Table 1). Figure $2 \mathrm{C}$ suggests that the polymer should be in the reduced and nonionic form at the potentials where the second reduction occurs. However, as will be discussed later, spectroscopic evidence suggested that the polymer still had a substantial amount of the oxidized pyrrole unit, even at these negative potentials, during the measurements (Fig. 3 B). Thus, the unreduced PPy unit can interact with the quinone trianion, shifting the $\mathrm{pc}_{2}$ to the positive potential:

$$
\left[\mathrm{Py}_{3}{ }^{+} \mathrm{AQS}^{2-} \cdot \mathrm{TEA}^{+}\right]_{n} \stackrel{+\mathrm{e}^{-}, \mathrm{TEA}^{+}}{\longrightarrow}\left[\mathrm{Py}_{3}{ }^{+} \mathrm{AQS}^{3-}\left(\mathrm{TEA}^{+}\right)_{2}\right]_{n}(3)
$$

Similar behavior in the peak potential of the $\mathrm{pc}_{2}$ has been observed for 9,10-anthraquinone-2,6-disulfonate (Table 1). In contrast to the quinone sulfonates, 2naphthalene sulfonate and $m$-nitrobenzene sulfonate in films did not exhibit substantial shifts when compared
Table 1 Electrochemical characteristics of polypyrrole/ anthraquinone sulfonate composite films on glassy carbon electrodes in $0.1 \mathrm{M}$ TEAP-DMSO

\begin{tabular}{lcc}
\hline Compound & $E_{\mathrm{pc1}} / \mathrm{V}$ & $E_{\mathrm{pc} 2} / \mathrm{V}$ \\
\hline $\mathrm{PPy} / \mathrm{Cl}^{-}$ & -0.23 & N.D. \\
$\mathrm{AQS}^{-}$ & -0.83 & -1.40 \\
$\mathrm{PPy} / \mathrm{AQS}^{-}$ & -0.50 & -1.20 \\
$\mathrm{AQ}\left(\mathrm{S}^{-}\right)_{2}$ & -0.80 & -1.40 \\
$\mathrm{PPy} / \mathrm{AQ}\left(\mathrm{S}^{-}\right)_{2}$ & -0.65 & -1.20 \\
$\mathrm{NS}^{-}$ & -2.50 & N.D. \\
$\mathrm{PPy}^{-} \mathrm{NS}^{-}$ & -2.50 & N.D. \\
$\mathrm{MS}^{-}$ & -1.68 & N.D. \\
$\mathrm{PPy} / \mathrm{MS}^{-}$ & -1.70 & N.D. \\
\hline
\end{tabular}

$E_{\mathrm{pc} 1}$ and $E_{\mathrm{pc} 2}$ are the first and second peak potentials referred to $\mathrm{Ag} / \mathrm{AgCl}$ (sat. $\mathrm{KCl}$ ). The concentration of the dissolved compounds were $5 \mathrm{mM}$. Abbreviations: $\mathrm{AQS}^{-}, 9,10$-anthraquinone2-sulfonate; $\mathrm{AQ}\left(\mathrm{S}^{-}\right)_{2}, 9,10$-anthraquinone-2,6-disulfonate; $\mathrm{NS}^{-}$, 2-naphthalene sulfonate; $\mathrm{MS}^{-}, m$-nitrobenzene sulfonate; N.D., not found.

to the dissolved sulfonates. The results can be explained in terms of the reduction potentials, which are much more negative than those of the quinone sulfonates. At these highly negative potentials, the polymer is reduced almost completely, so very few cationic sites should be available in the film. The potential shifts could also be explained in terms of the Donnan potential, accompanied by the introduction of the film on the electrode. However, this mechanism can be excluded because of the negligible shifts observed for naphthalene and nitrobenzene sulfonates. The positive shifts could also be assigned to trace water in the films, because they were prepared in aqueous solutions. However, this mechanism failed to explain the evidence that the PPy/AQS ${ }^{-}$films that had been soaked in DMSO or DMF for $24 \mathrm{~h}$ gave almost the same potential values as those used without such treatment.

The oxidation peak for the semiquinone did not appear in the cyclic voltammogram of PPy/AQS ${ }^{-}$as shown by the dashed curve in Fig. 2 C. As will be discussed later, $\mathrm{AQS}^{2-}$. is stable enough over periods of spectroscopic measurements, so the disappearance of the oxidation peak should not be due to a follow-up reaction for the semiquinone. Presumably, the anodic peak was merged into the anodic peak of PPy polymer, which appeared above $0 \mathrm{~V}$ for the PPy/AQS- film, and the anodic peak at around $-0.5 \mathrm{~V}\left(\mathrm{pa}_{2}\right)$ can be assigned to the oxidation of trianion. Obviously, both the PPy and $\mathrm{AQS}^{-}$show slower electron transfer with the electrode, when made into a composite film. The correlation coefficients between the cathodic peak height and the square root of the scan rate were more than 0.95 over $10-100 \mathrm{mV} \mathrm{s}^{-1}$.

\section{Spectroelectrochemistry of PPy/AQS ${ }^{-}$composite films}

The semiquinone radical $\mathrm{AQS}^{2-}$. dissolved in $0.1 \mathrm{M}$ TEAP-DMF on an Au semitransparent electrode was purple in color and had a strong absorption band, which 
is characteristic of $\mathrm{AQS}^{2-}$, with a maximum at $565 \mathrm{~nm}$. The spectra also indicated that the semiquinone radical was quite stable over periods of spectral measurements. Audebert et al. studied the cyclic voltammetry and spectroelectrochemistry of the 6-(pyrrol-1-yl) hexyl9,10-anthraquinone-2-sulfonate monomer and polymer in $0.1 \mathrm{M} \mathrm{LiClO}_{4}$-DMSO. ${ }^{20}$ The film electropolymerized on an optically transparent electrode exhibited an absorption band at almost the same wavelength as that for the monomer.

Figure 3A shows the potential dependence of absorbance at $565 \mathrm{~nm}$ for $\mathrm{AQS}^{-}$dissolved in $0.1 \mathrm{M}$ TEAPDMF. The sharp increase in absorbance at $-0.7 \mathrm{~V}$ is due to the formation of $\mathrm{AQS}^{2--}$ radical, and the decrease below $-1.0 \mathrm{~V}$ can be attributed to the formation of $\mathrm{AQS}^{3-}$, which was yellowish brown in color. Figure $3 \mathrm{~B}$ illustrates the absorbance-potential curves for the $\mathrm{PPy} / \mathrm{Cl}^{-}$and $\mathrm{PPy} / \mathrm{AQS}^{-}$films, and the relative increase for the $\mathrm{PPy} / \mathrm{AQS}^{-}$film indicates the formation of $\mathrm{AQS}^{2-}$. in the film. Here, the decrease in the absorbance of $\mathrm{PPy} / \mathrm{Cl}^{-}$with a decrease in the potential can be assigned to the reduction of PPy, which agrees with the voltammetric results in Fig. 2B. However, Fig. 3B shows that below the reduction potential $(-0.23 \mathrm{~V})$, absorbance of $\mathrm{PPy} / \mathrm{Cl}^{-}$(b) decreases only gradually with a decrease in the potential and that a substantial number of the cationic (oxidized) sites are still present

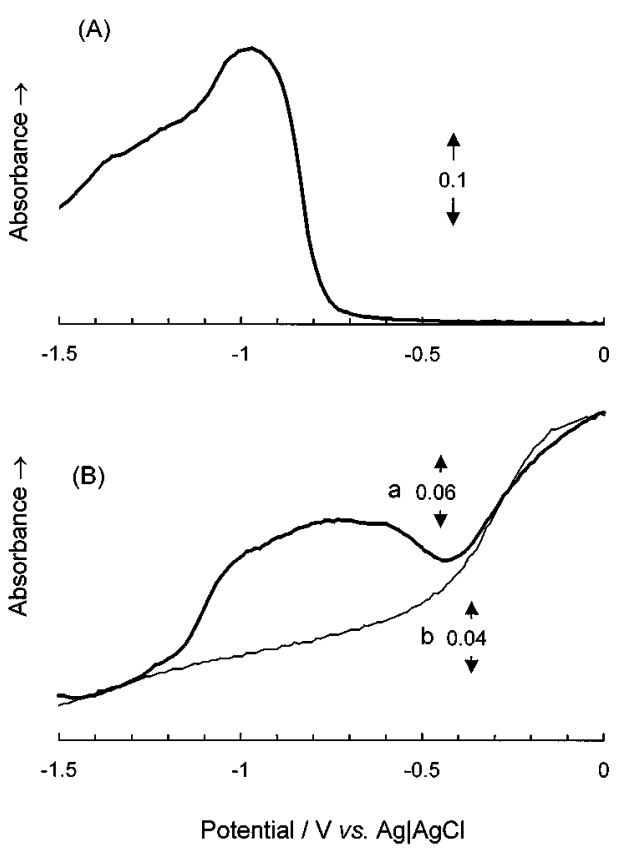

Fig. 3 Absorbance $v s$. potential curves of (A) $5 \mathrm{mM} \mathrm{AQS}$ dissolved in 0.1 M TEAP-DMF and (B) PPy films monitored at $565 \mathrm{~nm}$ on Au plastic film electrodes: In (B), the curves a and $\mathrm{b}$ show the absorbance of the PPy/AQS ${ }^{-}$and $\mathrm{PPy} / \mathrm{Cl}^{-}$ films. Since precise control of the film thickness was difficult, the absorbance of two films was normalized to give the same value at $0 \mathrm{~V}$. All the spectra given here are after the base line corrections for the Au-plastic electrodes. Electrodeposition of PPy, $+0.8 \mathrm{~V}$ for $1 \mathrm{~min}$. at $-1.2 \mathrm{~V}$. As a result, the absorbance-potential curve (a) shifted towards more positive potentials than that for the dissolved quinone (A) because of the interaction between the cationic site and $\mathrm{AQS}^{2-}$. . The ion pairing with $\mathrm{AQS}^{3-}$ is also likely at a potential as negative as $-1.2 \mathrm{~V}$, since the reduction of the PPy matrix is often slow.

\section{Cationic exchange in PPy/AQS film}

When conducting polymers are reduced to their nonionic states, large anions doped in the polymers are not ejected completely or at all from polymer texture. As a result, cations in solution are inserted into the texture to compensate for the anionic charges of the dopants, and the polymers behave like cation exchangers. Consequently, a similar property is expected for PPy/AQS ${ }^{-}$, although the cation exchange should be potential dependent because of $\mathrm{AQS}^{-}$undergoing the redox reactions. In this section, we discuss the exchange properties of the PPy/AQS ${ }^{-}$film and hence ion pairing between $\mathrm{AQS}^{2-}$. and $\mathrm{Li}^{+}$ion in the film.

Figure 4 illustrates the dependence of voltammetric behavior on the concentration of $\mathrm{Li}^{+}$ion for the dissolved $\mathrm{AQS}^{-}$(A) and PPy/AQS- (B), where $\mathrm{Li}^{+}$ion was added to examine if there would be some ion pairs formation with the reduced quinone. Ion pairing for many semiquinone systems has been successfully studied by assuming EC mechanisms, and the positive shifts of $\mathrm{pc}_{1}$ with an increase in the $\mathrm{Li}^{+}$concentration can be analyzed similarly. ${ }^{33,34}$

$$
\begin{aligned}
& \mathrm{Py}_{3}{ }^{+} / \mathrm{AQS}^{-}+\mathrm{e}^{-} \rightleftharpoons \mathrm{Py}_{3}{ }^{+} / \mathrm{AQS}^{2-} \cdot \\
& \mathrm{Lii}^{+}+\mathrm{Py}_{3}{ }^{+} / \mathrm{AQS}^{2-} \cdot \rightleftharpoons \mathrm{Py}_{3}{ }^{+} /\left(\mathrm{Li}^{+}\right)_{p} \mathrm{AQS}^{2-} .
\end{aligned}
$$

where $\left(\mathrm{Li}^{+}\right)_{p} \cdot \mathrm{AQS}^{2-}$. is the ion pair formed in the film and $p$ is the stoichiometric coefficient, and the association of $\mathrm{AQS}^{2-}$. with $\mathrm{TEA}^{+}$is neglected, as has been assumed in the previous section. The association constant $K$ for Eq. (5) is given as follows:

$$
K=\frac{\left[\left(\mathrm{Li}^{+}\right)_{p} \mathrm{AQS}^{2-\cdot}\right]}{\left[\left(\mathrm{Li}^{+}\right)\right]^{p}\left[\mathrm{AQS}^{2-\cdot}\right]}
$$

The shift in the half-wave potential, $\Delta E_{1 / 2}$ with respect to the ion pair formation can be expressed approximately by the following equation: ${ }^{33}$

$$
\Delta E_{1 / 2}=\frac{R T}{F} \ln K+\frac{R T}{F} p \ln C_{\mathrm{Li}^{+}}
$$

where $C_{\mathrm{Li}}$ is the concentration of $\mathrm{Li}^{+}$ion in the bulk solution, $\Delta E_{1 / 2}$ is the difference in the potential between the PPy/AQS- films with and without $\mathrm{Li}^{+}$ion, and the other symbols have their standard meanings. Equation (7) predicts that, if there is an ion pair interaction, $E_{1 / 2}$ will vary linearly with respect to $\log C_{\mathrm{Li}+}$. The interaction between the $\mathrm{Py}_{3}{ }^{+}$and $\mathrm{AQS}^{2-}$, which coincides with Eq.(5), should have no effect on the potential, as long 

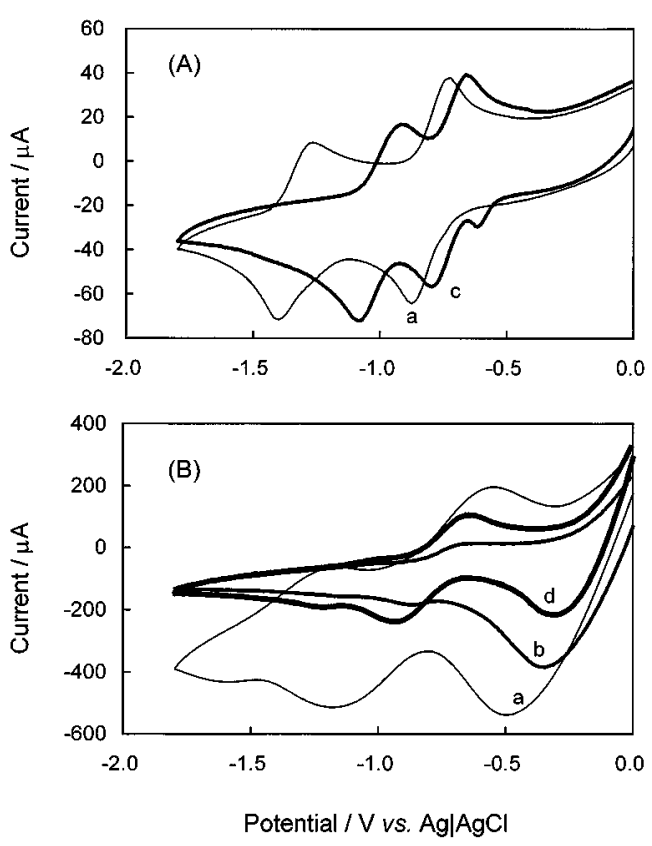

Fig. 4 Cyclic voltammograms of (A) $5 \mathrm{mM} \mathrm{AQS}^{-}$dissolved in DMF and (B) the PPy/AQS- film at scan rates of (A) 50 $\mathrm{mV} \mathrm{s}^{-1}$ and (B) $10 \mathrm{mV} \mathrm{s}^{-1}$. The $\mathrm{Li}^{+}$ion concentrations are (a) 0.0 , (b) 0.05 , (c) 0.10 , and (d) $0.30 \mathrm{M}$. The ionic strength was adjusted to 0.30 with TEAP. Electrodeposition of PPy, +0.8 $\mathrm{V}$ for $5 \mathrm{~min}$

as $\Delta E_{1 / 2}$ is used.

Figure $4 \mathrm{~B}$ shows the voltammograms of the PPy/ $\mathrm{AQS}^{-}$film at different $\mathrm{Li}^{+}$concentrations. Successive decreases in the currents and positive shifts of the peaks were observed on the addition of $\mathrm{Li}^{+}$ion. When the concentration of $\mathrm{Li}^{+}$ion was increased from 0.0 to $0.30 \mathrm{M}$, the potential of the first cathodic peak shifted about $200 \mathrm{mV}$ to the positive direction. The shifts confirm the ingress of $\mathrm{Li}^{+}$ion into the film to counterbalance the negative charge arising from the quinone reduction. Therefore, the PPy/AQS- film worked as a cation-exchanger at electrode potentials more negative than the onset potential of the first quinone reduction (ca. $-0.3 \mathrm{~V}$ vs. $\mathrm{Ag} / \mathrm{AgCl})$. The $p$ and $K$ values for the semiquinone dissolved in DMF were evaluated to be 0.93 and $74 \mathrm{M}^{-1}$ and agreed well with the values that have been reported for the ion pairs of semiquinones in DMF. ${ }^{33,34}$ Although Eq. (7) would not allow the evaluation of the accurate $p$ and $K$ values for PPy/AQS because of the quasi-reversible nature of electron transfer, we evaluated tentative $p$ and $K$ values of 1.2 and $1.1 \times 10^{3} \mathrm{M}^{-1}$ for the ion pair in the film. The marked increase in the $K$ value on the incorporation, which is also indicated by the comparison of Fig. 4A with Fig. $4 \mathrm{~B}$, seems to be more than the experimental uncertainties arising from the slow electron transfer. The reason for the increase of $K$ is not clear, but the formation of a more compact film may be responsible. The polymer texture would become less polar by the formation of the contact ion pairs, leading to a more compact film by the ejection of dipolar DMF molecules and bulky $\mathrm{TEA}^{+}$ ion. The decreases in the currents on the addition of $\mathrm{Li}^{+}$ion might also be explained in terms of the formation of the compacted films arising from ejecting the electrolyte and DMF from the film (Fig. 4B).

\section{References}

1. P. N. Batlett and R. G. Whitaker, J. Electroanal. Chem., 224, 27 (1987).

2. P. N. Batlett and R. G. Whitaker, J. Electroanal. Chem., 224, 37 (1987).

3. A. Rudge, I. Raistrick, S. Gottesfled and J. P. Ferraris, J. Electrochim. Acta, 39, 273 (1993).

4. A. Mogammadi, O. Inganas and I. Luundstrom, $J$. Electrochem. Soc., 133, 947 (1986).

5. T. Shimidzu, A. Ohtani, T. Iyoda and K. Honda, J. Chem. Soc. Chem. Commun., 1987, 327.

6. S. Panero, P. Prosperi, B. Klaptse and B.Scrosati, J. Electrochim. Acta, 31, 158 (1986).

7. S. C. Yang, "Large-Area Chromogenics: Materials and Devices for Transmittance Control", ed. C. M. Lampert, C. G. Granqvist and S. R. F. Potter, Vol. 1S-4, p. 335, The International Society for Optical Engineering, Bellingham, U.S.A., 1990.

8. T. Kobayashi, H. Yoneyama and H. Tamura, J. Electroanal. Chem., 161, 419 (1984).

9. F. Garnier, G. Tourillon, M. Gazard and J. C. Dubois, J. Electroanal. Chem., 148, 299 (1983).

10. J. Waltman, A. F. Diaz and J. Bargon, J. Electrochem. Soc., 131, 740 (1984).

11. S. Kuwabata, H. Yoneyama and H. Tamura, Bull. Chem., Soc. Jpn., 57, 2247 (1984).

12. R. Bjorklund, S. Andersson, S. Allenmark and I. Lundstroem, J. Mol. Cryst., 121, 263 (1985).

13. A. Kitani, J. Yano and K. Sasaki, J. Electroanal. Chem., 209, 227 (1986).

14. H. Yashima, M. Kobayashi, K. B. Lee, D. Chung, A. J. Heeger and F. Wuldl, J. Electrochem. Soc., 134, 46 (1987).

15. A. F. Diaz, K. K. Kanazawa and G. P. Gardini, J. Chem. Soc. Chem. Commun., 1979, 635.

16. K. K. Kanazawa and A. F. Diaz, R. H. Geiss, W. D. Gill, J. F. Kwak, J. A. Logan, J. F. Rabolt and G. B. Street, J. Chem. Soc., Chem. Commun., 1979, 854.

17. A. F. Diaz, J. Chem. Str., 17, 145(1981).

18. T. Iyoda, A. Ohtani, T. Shimidzu and K. Honda, Synth. Met., 18, 725 (1987).

19. T. Shimidzu, A. Ohtani, M. Aiba and K. Honda, J. Chem. Soc., Faraday Trans. 1, 84, 3941 (1988).

20. P. Audebert, G. Bidan and M. Lapkowski, J. Chem. Soc., Chem. Commun., 1986, 887.

21. T. Nagaoka, N. Nishii, K. Fujii and K. Ogura, J. Electroanal. Chem., 322, 383 (1992).

22. E. M. Genies and M. Marchesiello, Synth. Met., 55-57, 3677 (1993).

23. T. Ikeda, I. Katasho and M. Senda, Anal. Sci., 1, 445 (1985).

24. C. P. Andrieux and P. Audebert, J. Electroanal. Chem., 285, 163 (1990).

25. C. P. Andrieux, P. Audebert and C. Salou, J. Electroanal. Chem., 318, 235 (1991).

26. J. Grimshaw and S. D. Perera, J. Electroanal. Chem., 265 , 335 (1989). 
27. S. Kuwabata, K. Okamoto, O. Ikeda and H. Yoneyama, 32. B. J. Feldman, P. Burgmayer and R. W. Murray, J. Am. Synth. Met., 18, 101 (1987). Chem. Soc., 107, 872 (1985).

28. G. R. Mitchell, F. J. Davis, R. Cywinski and A. C. Hanon, 33. M. E. Peover and J. D. Davies, J. Electroanal. Chem., 6, 46 J. Polym. Commun., 30, 98 (1989).

29. G. R. Mitchell, F. J. Davis and C. H. Legge, Synth. Met., 26, 247 (1988).

30. M. Hepel, J. Electrochim. Acta, 41, 63 (1996).

31. R. Senthurchelvan, Y. Wangs, S. Basak and K. Rajeshwar, J. Electrochem. Soc., 143, 44 (1996). (1963).

34. T. Nagaoka, S. Okazaki and T. Fujinaga, J. Electroanal. Chem., 133, 89 (1982).

(Received November 17, 1997)

(Accepted February 13, 1998) 